\title{
Influence of nicotine upon human brain metabolism, an in vivo noninvasive Near Infrared Spectroscopy (NIRS) study.
}

Francesco Crespi

Voltammetry-NIRS Lab, Medicine Center, Verona, Italy.

*Corresponding Author: Francesco Crespi, Voltammetry - NIRS Lab., Medicine Center, Verona, Italy.

Received date: October 11, 2021; Accepted date: October 20, 2021; Published date: October 27, 2021

Citation: Francesco Crespi. (2021) Influence of nicotine upon human brain metabolism, an in vivo noninvasive Near Infrared Spectroscopy (NIRS) study. Clinical Research and Clinical Trials. 4(4); DOI: 10.31579/2693-4779/067

Copyright: (C) 2021 Francesco Crespi, This is an open access article distributed under the Creative Commons Attribution License, which permits unrestricted use, distribution, and reproduction in any medium, provided the original work is properly cited.

\begin{abstract}
Nicotine, a natural alkaloid derived from tobacco, is involved in various outcomes ranging from addiction to toxicity and/or neuro-protective actions.

Nevertheless, the literature on the effects of nicotine administration upon the activity of brain regions is mixed; either increased, decreased, or no overall effect was reported when being evaluated by various methodologies such as positron emission tomography (PET), functional Magnetic Resonance Imaging (fMRI).

In this work, Near Infrared Spectroscopy (NIRS) is applied as it allows monitoring oxygen saturation in the living tissue as well as changes in oxygenation of hemoglobin and when applied on brain studies, it gives indications of cerebral haemo-dynamics as well as brain metabolism.

In particular, here NIRS has been applied in human volunteers as this methodology is based upon the use of harmless radiations so that to provide a non-invasive, non-ionizing procedure to monitor 2 main forms of haemoglobin: oxyhaemoglobin (HbO2) and deoxy-haemoglobin $(\mathrm{Hb})$.

The data gathered indicate an overall positive influence of nicotine upon $\mathrm{HbO} 2$ levels, as well as total blood volume (V) therefore suggesting an increased brain metabolism.

Finally these data further propose NIRS with its characteristics of noninvasiveness, easy to-use, portable, restraint-free therefore relatively psychologically undemanding, as replicable and ideal methodology for clinical applications and translational approaches.
\end{abstract}

Key words: NIRS; human volunteers; haemoglobin; brain metabolism.

\section{Introduction}

Various works have analyzed the influence of nicotine upon brain activity. In particular, different studies have shown that nicotine causes a small overall reduction in global cerebral metabolism of glucose in healthy tobacco smoking adult male volunteers as monitored by positron emission tomography (PET) [1,2].

Furthermore, experimental studies performed in rodents have shown that nicotine and/or electronic cigarette (E-Cig) exposure induce a state of glucose deprivation at the neurovascular unit because of decreases brain glucose uptake under normoxic and ischemic conditions along with down-regulation of GLUT1 and GLUT3 expressions [3].

A different approach to assess central nervous system actions of nicotine is by the use of cerebral blood flow $(\mathrm{CBF})$ measurement i.e. by means of [O-15]-labeled water and PET [4] or using functional Magnetic Resonance Imaging (fMRI) [5].
A variety of effects either increase, decrease or none have been shown (for a review see REF 6).

\section{For istance:}

- A significant fall in CBF was observed by transcranial Doppler ultrasound in six volunteers as resulting of the immediate effects of smoking [7]

- In contrast various authors have reported localized increases in CBF after nicotine administration, for example, Nagata et al (1995) using brain imaging showed a significant increase in CBF after cigarette smoking, mainly in the frontal lobes and cerebellum [8].

Stein et al (1998) found fMRI activation in brain areas involved in reinforcement, following i.v. treatment with nicotine [9]. 
- Other works reported mixed effects: i.e. using PET in habitual smokers receiving nasal nicotine spray it appeared increased blood flow in the right hemisphere thalamus, but decreased blood flow in the left anterior temporal cortex and right hemisphere amygdala [10]. Similar observations were reported in healthy volunteer smokers when exposed to nicotine-containing cigarette as well as receiving intravenous nicotine injections $[11,12]$.

Finally, no overall effect of nicotine upon CBF was also reported in normal adults with a smoking habit during cigarette smoking $[13,14]$.

In order to analyze further the influence of nicotine possibly in the attempt to better clarify its effect upon brain metabolism here the methodology of NIRS has been applied in human volunteers.

NIRS is indeed a non-invasive non-ionizing technique that can be used to monitor oxygen saturation in the living tissue as well as changes in oxygenation of hemoglobin $[15,16]$. Importantly, the absorption spectra of near-infrared light differ for the oxygenation-deoxygenation states of hemoglobin (oxygenated form $\mathrm{HbO} 2$ vs.deoxygenated form $\mathrm{Hb}$, respectively) so that the two compounds can be directly monitored. Such total haemoglobin concentration $(\mathrm{HbO} 2+\mathrm{Hb})$ is considered as total blood volume (THC or V) [17]. All together, these measurements are indicative of the state of vascular activity and the state of the metabolism in the tissue analyzed.

\section{Methods}

The NIRS apparatus used in this work has been described earlier [18], briefly, a schematic configuration of the NIRS system consists of four main blocks: the optical head (optic fibers laser sources and the receiver), the emitter unit, the receiver unit, and the control unit. The optical head is placed onto the surface of the tissue under test in order to monitor noninvasively the oxygenation.

Four healthy tobacco smoking adult male volunteers (aged 27-29) smoking either few or number of cigarettes daily (from 1 up to 12) were prepared for NIRS measurements as described earlier [19], briefly they were wearing a cap in which the optic fibers and the receiver were embedded so that external light cannot influence the measurements (see scheme in figure 1).
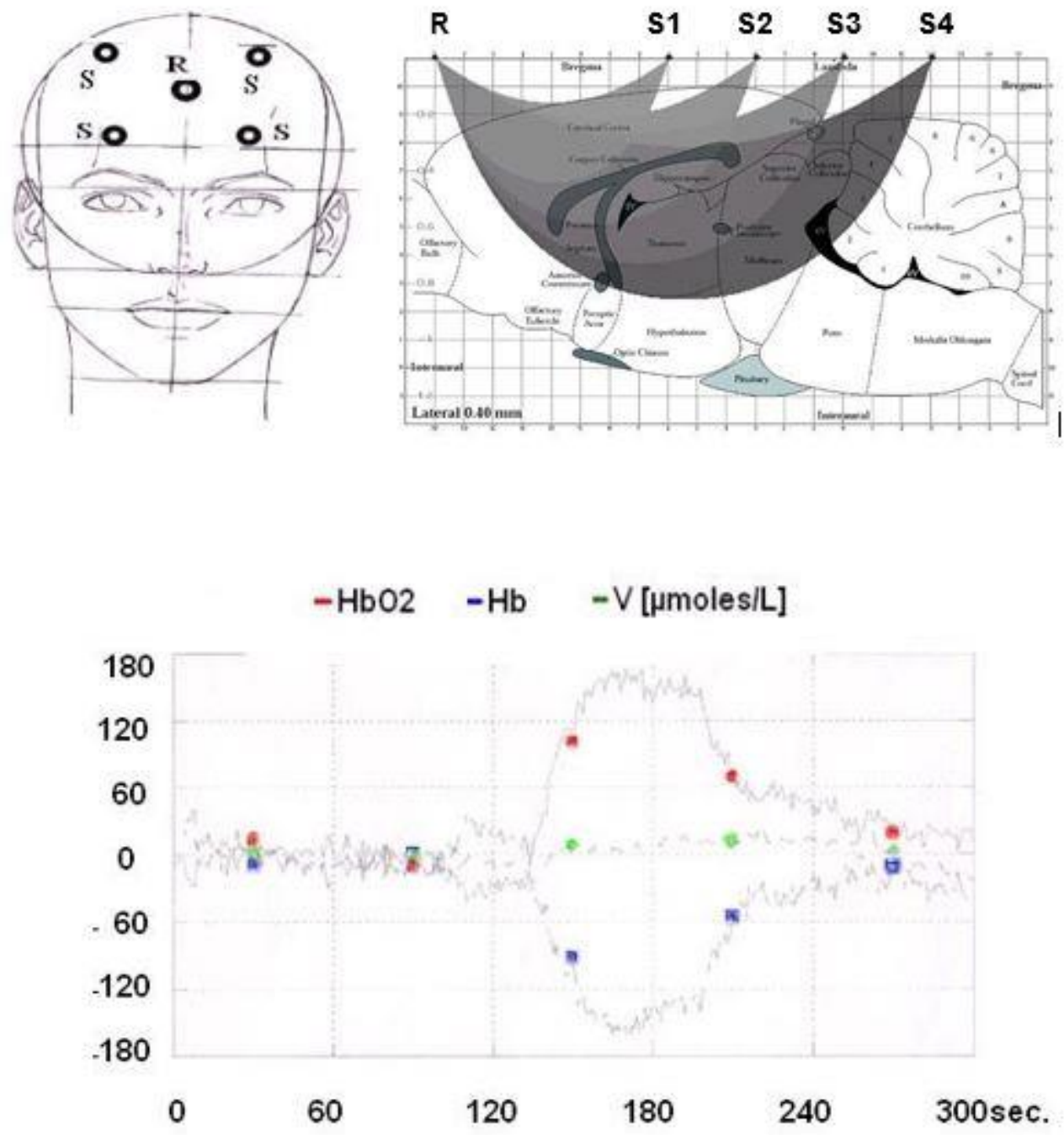

TOP left: Scheme of the positioning of the receiver R and of the four laser sources (S).

$\mathrm{R}$ and $\mathrm{S}$ are deeply embedded in a cap to avoid influence of external light (not shown).

TOP right : Theoretical brain areas monitored in the brain i.e. computer simulation of photon paths based on photon migration theory [21, 22). 
BOTTOM: Response of NIRS parameters to exogenous supply of pure oxygen ( 1 min from 120 to $180 \mathrm{sec}$ ) shown as changes from basal levels that are recorded from zero to $120 \mathrm{sec}$ and that are normalized as $=$ zero $\mu$ moles/L. Colored symbols are inserted to facilitate the observation of the continuous recordings. This graphic has been obtained in one volunteer. Similar traces have been observed in all the volunteers.

\section{Figure 1: In vivo non-invasive NIRS measurements in man.}

The optical components were positioned in order to involve the cortical region of the brain accordingly to previous work indicating this area among the most negatively sensitive to nicotine [20].

The protocol of the experiment was as follow: 10min recordings for control baseline of the three parameters monitored i.e. $\mathrm{HbO} 2, \mathrm{Hb}, \mathrm{HbT}$ (or V). During this period the volunteers were asked to mimic the smoking act, in order to inspect the influence of forced air inhalation upon NIRS parameters. Successively the volunteers were asked to smoke during $5 \mathrm{~min}$. Then measurements were continued other $10 \mathrm{~min}$.

Ethical clearance and permission was obtained from the Ethical Review Committee of Public Health and Medical Sciences. Data were collected from the participants after getting informed consents. All the information obtained in due time were kept confidentially.

\section{Statistics}

Statistical analysis have been performed using Statistica 6. Row data were subjected to ANOVA, with comparison between "control period" and "treatment period" values (one-way ANOVA and Dunnett test).

Results are presented as $\mu$ moles/L, mean \pm s.e.m., $\mathrm{p}<0.05$.

\section{Results}

In figure 1 the positioning of the Receiver $(\mathrm{R})$ and the four laser Sources (S) is shown as well as the theoretical brain areas of brain that can be monitored when using such positioning accordingly to computer simulation of photon paths based on photon migration theory [21, 22]. Furthermore, the response of NIRS parameters to exogenous supply of pure oxygen ( $1 \mathrm{~min}$ from 120 to $180 \mathrm{sec}$ ) is shown as continuous changes from basal levels that are recorded from zero to $120 \mathrm{sec}$ and that are normalized as $=$ zero $\mu$ moles $/ \mathrm{L}$. This graphic has been obtained in one volunteer. It is evident the large increase of $\mathrm{HbO} 2$ to approximately $+150 \mu \mathrm{mole} / \mathrm{L}$, the parallel decrease of $\mathrm{Hb}$ to approximately $-150 \mu \mathrm{mole} / 1$, while no significant modification of $\mathrm{V}$ is observed.

Similar traces have been observed in all the volunteers.

\section{$-\mathrm{HbO2}[\mu \mathrm{moles} / \mathrm{L}]-\mathrm{Hb}[\mu \mathrm{moles} / \mathrm{L}]-\mathrm{V}[\mu \mathrm{moles} / \mathrm{L}]$}

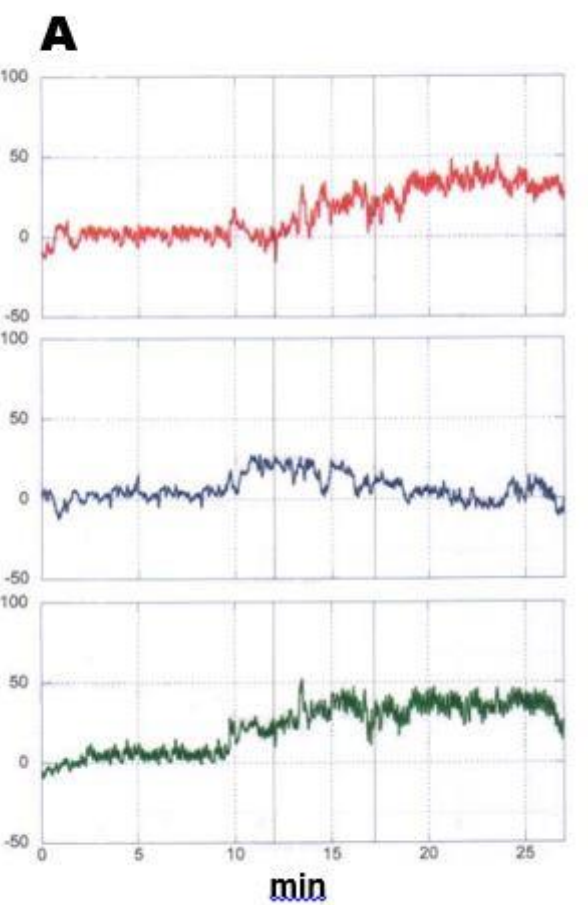

\section{B}
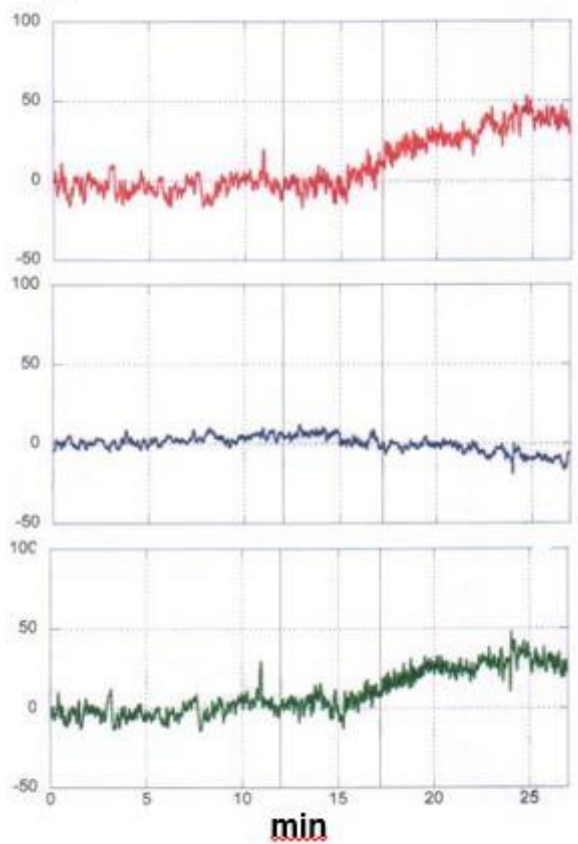

Figures 2 A-D illustrate the evolution of the three NIRS values detected continuously in each of the four volunteers, respectively before (0 to $10 m i n$, control time) and following the smoking time i.e. 5 min of smoking and then additional 10 min recordings. 

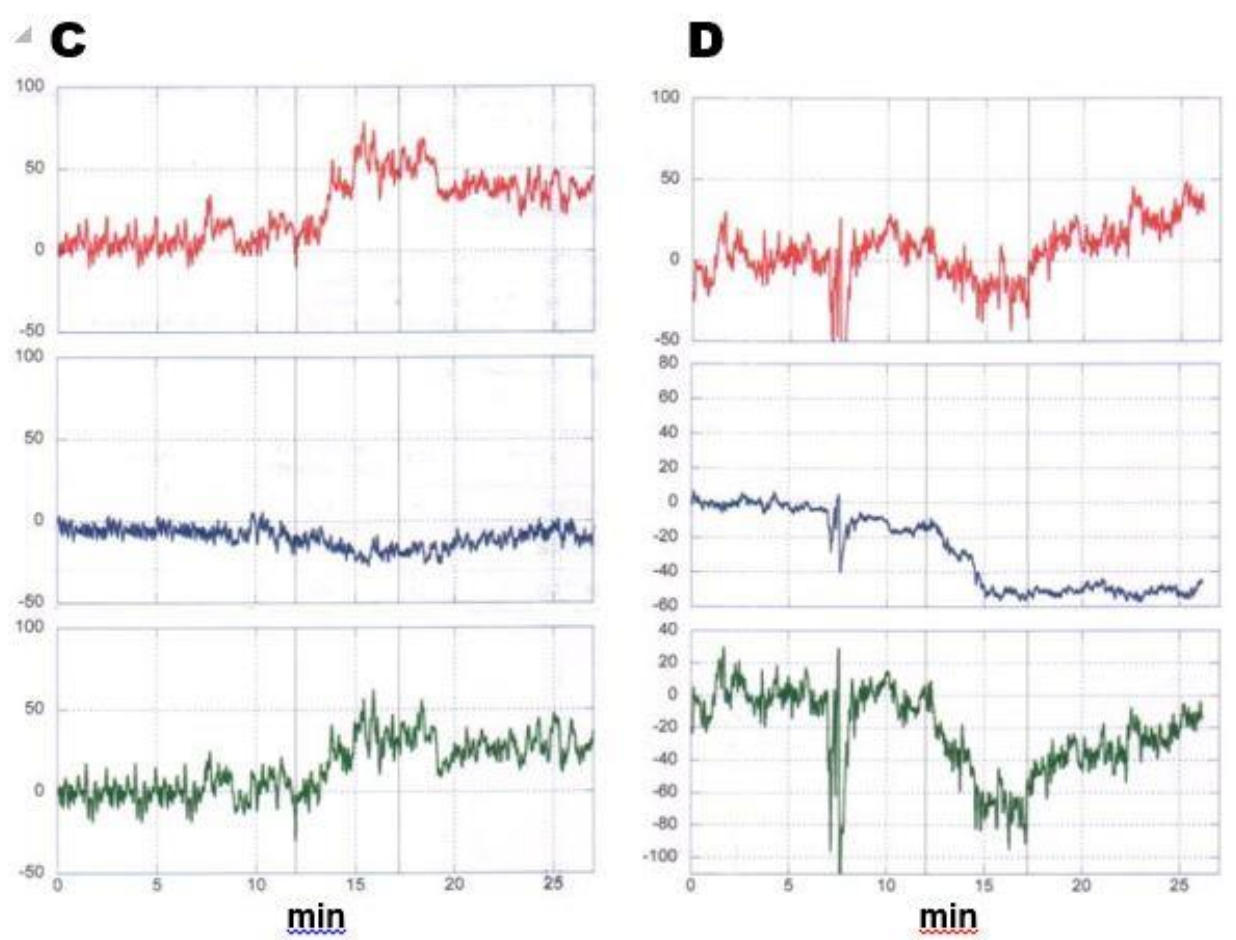

Figure 2 A-D: Evolution of the NIRS parameters monitored in four healthy tobacco smoking adult male volunteers (A, B, C, D) smoking either few or number of cigarettes daily (see Table 1).

Protocol of the experiment: first 10min recordings for control baseline of the three parameters monitored i.e. $\mathrm{HbO} 2, \mathrm{Hb}$, $\mathrm{HbT}$ (or V) i.e. red, blue or green line respectively. During this period the volunteers were asked to mimic the smoking act, in order to examine the influence of forced air inhalation upon NIRS parameters. Successively the volunteers were asked to smoke during $5 \mathrm{~min}$. Then measurements were continued other $10 \mathrm{~min}$. Note that forced air inhalation did not modify significantly any of then3 NIRS parameters i.e. HbO2, Hb, V. oppositsely, smoking was followed by significant modifications of these parameters (see also Figure 3).

It appeared that mimicking the smoking act did not influence NIRS parameters in any one of the volunteers, in contrast $\mathrm{HbO} 2$ was significantly increased in all subjects, in particular when taking into account the volunteers \#1, 2, 3 that were avoiding large movements (i.e. walking around, gesticulation, volunteer \#4) while under recordings (see Table 1).

\begin{tabular}{|l|l|c|l|}
\hline name & age & cigarettes/day & notes \\
\hline Volunteer 1 & 27 & $1-2$ & steady \\
\hline Volunteer 2 & 28 & $6-8$ & steady \\
\hline Volunteer 3 & 29 & $8-10$ & steady \\
\hline Volunteer 4 & 27 & $10-12$ & large movements \\
\hline
\end{tabular}

Table 1: Indicates the age and the smoking habit of each volunteer and the behavior of each one while under NIRS monitoring.

In figure 3 the mean of the data gathered in the four volunteers is shown. It appeared that both $\mathrm{HbO} 2$ and volume $\mathrm{V}$ are significantly increased within $20-25$ min following smoking up to approximately 45 and 38 $\mu$ mole/l, respectively, when considering basal levels as $=$ zero $\mu$ moles $/ \mathrm{L}$. 


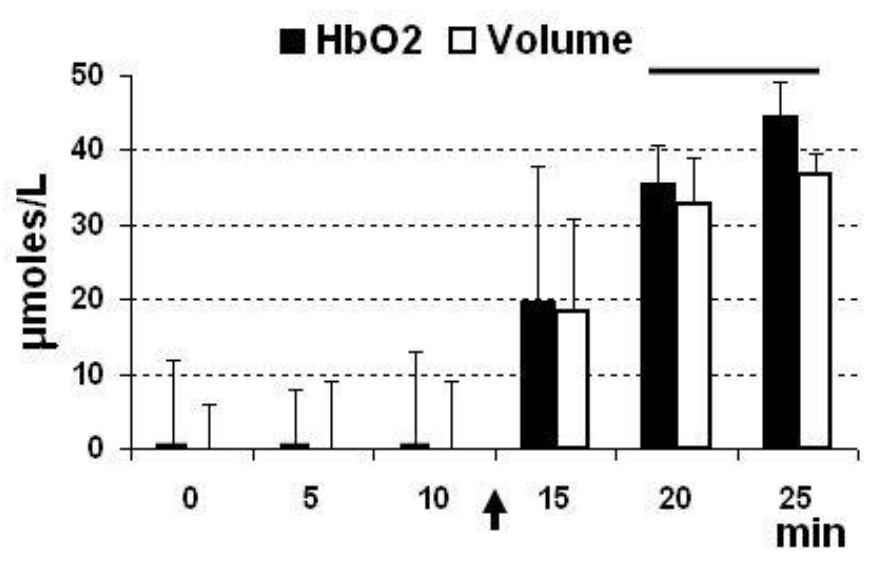

Figure 3: In the four volunteers smoking was followed by significant increase of HbO2 and V within 5-10 min, while Hb levels were not affected significantly overall. See also Figure 2 showing the evolution of the NIRS parameters monitored in each volunteer. Data are expressed as $\mu$ moles/L, mean \pm s.e.m. Statistical analysis (one-way ANOVA and Dunnett test) show significant changes versus control period, bar: $p<0.05$.

\section{Discussion}

The natural alkaloid nicotine, derived from tobacco, is involved in addictive effects [23], toxic effects [24, 25] and neuro-protective actions $[26,5,19,32]$.

Nevertheless and as underlined in the Introduction, the literature on the effects of nicotine administration on the activity of brain regions is mixed; either increased, decreased, or no overall effect was reported in particular when evaluated by CBF analysis.

In this work, NIRS is applied as it allows monitoring oxygen saturation in the living tissue as well as changes in oxygenation of hemoglobin (15, 16). In particular, when applied on brain studies, it gives indications of cerebral haemo-dynamics as well as brain metabolism as already demonstrated $[18,28]$.

The data gathered indicate an overall positive influence of nicotine upon $\mathrm{HbO} 2$ levels, therefore possibly upon brain metabolism. This is further supported by the observation of increased values of the volume (NIRS parameter $\mathrm{V}$ ) that could be related to a vasodilator influence of nicotine. Indeed, Uchida and Hotta have reported enhanced cerebral flow in the cortex of anesthetized rats treated with nicotine [29]. Such effect has been related to the capability of nicotine to activate the nitric oxide system that is indeed inducing vasodilatation in brain [30] following activation of nicotinic receptors [29, 31].

In a previous work performed in anaesthetised rodents prepared for NIRS analysis, a positive effect of nicotine treatment upon $\mathrm{HbO} 2$ levels was detected in the similar progressive manner as obtained here in man with a maximum increase obtained 20-25 min later [32].

Another in vivo non-invasive methodology such as functional magnetic resonance imaging (fMRI) has employed nicotine as a prototypical agent for the analysis of drug-induced changes in the human brain [33, 34].

It resulted increase in brain activity in particular in cortical and sub cortical regions that is also temporally consistent with the NIRS data presented here.

These results, together with our previous data with other drugs of abuse $[5,19,32]$, support the applicability of NIRS for direct measurement of turnover of endogenous oxygen that is directly related to neuronal functions coupled with blood flow. In such application NIRS might be complementary to fMRI capabilities, with some advantages versus fMRI that are: no need for 'tracers", for the subject to be completely immobile, no noise, small dimensions of the instrumentation which is mobile and portable, but most of all direct detection of both $\mathrm{HbO} 2$ and $\mathrm{Hb}$; fMRI measures $\mathrm{Hb}$ only.

Within the recent decades, more and more studies are using NIRS to analyse the neural mechanisms underlying more and more subtle (i.e. functional, cognitive, perceptual) brain functions in man $[35,36]$. In this contest, the NIRS methodology with the characteristics of noninvasiveness, easy to-use, portable, restraint-free therefore relatively psychologically undemanding, and replicable [37] is ideal for clinical applications and translational approaches [38].

Finally, the present results obtained in man together with our recent data achieved with NIRS both in rodents and man [19] support NIRS as a valuable tool for analysis of brain etabolism and its reliable efficacy on direct, rapid translational studies from animals to man.

Acknowledgment to Francesco Congestri for technical support.

\section{References}

1. Domino EF, Minoshima S, Guthrie SK, Ohl L, Ni L, Koeppe RA et al. (2000). Effects of nicotine on regional cerebral glucose metabolism in awake resting tobacco smokers. Neuroscience. 101: 277-282.

2. Stapleton JM, Gilson SF, Wong DF, Villemagne VL, Dannals RF, Grayson RF et al. (2003). Intravenous nicotine reduces cerebral glucose metabolism: a preliminary study. Neuropsychopharmacology. 28: 765-772.

3. A.E. Sifat, B.Vaidya, M.A. Kaisar, L. Cucullo, T. J. Abbruscato. (2018). Nicotine and electronic cigarette (E-Cig) exposure decreases brain glucose utilization in ischemic stroke J. Neurochemistry. 147,2: 204-221.

4. Fox PT, Mintun MA, Raichel ME, Miezin FM, Allman JM, Van Essen DC. (1986). Mapping the human visual cortex with positron emission tomography. Nature. 323: 806-809.

5. Crespi F, Formenti F, Congestri F. (2018). Near Infrared Spectroscopy alike Magnetic Resonance Imaging: Complementary Data in Rat Brain after Cocaine Treatment. J. Neurodegenerative Disorders. 2(1): 39-47. 
6. Mathew RJ, Wilson WH. (1995). Acute pharmacological effects of tobacco smoking and nicotine on cerebral circulation. In: Domino EF (ed). Brain Imaging of Nicotine and Tobacco Smoking. NPP Books: Ann Arbor. 109-121.

7. Cruikshank JM, Neil-Dweyer G, Dorrance DE, Hayes Y, Patel S. (1989). Acute effects of smoking on blood pressure and cerebral blood flow. J Hum Hypertens. 3: 443-449.

8. Nagata K, Shinohara T, Kanno I, Hatazawa J, Domino EF. (1995). Effects of tobacco cigarette smoking on cerebral blood flow in normal adults. In: Domino EF (ed). Brain Imaging of Nicotine and Tobacco Smoking. NPP Books: Ann Arbor, MI. 95-107.

9. Stein EA, Pankiewicz J, Harsch HH, Cho JK, Fuller SA, Hoffmann RG et al. (1998). Nicotine-induced limbic cortical activation in the human brain: a functional MRI study. Am J Psychiatry. 155: 1009-1015.

10. Zubieta J, Lombardi U, Minoshima S, Guthrie S, Ni L, Ohl LE et al. (2001). Regional cerebral blood flow effects of nicotine in overnight abstinent smokers. Biol Psychiatry. 49: 906-913.

11. Rose JE, Behm FM, Westman EC, Mathew RJ, London ED, Hawk TC et al. (2003). PET studies of the influences of nicotine on neural systems in cigarette smokers. Am J Psychiatry. 160: 323-333.

12. Rose JE, Behm F, Salley A. J.E. Bates, R.E. Coleman, T.C. Hawk, T.G. Turkington. (2007). Regional Brain Activity Correlates of Nicotine Dependence. Neuropsychopharmacol. 32: 2441-2452.

13. Solti F, Peter A, Olah I, Iskum M, Rev J, Hermann R et al. (1963). Effect of nicotine on cerebral blood flow and cerebral venous pressure. Cor Vasa. 5: 197-202.

14. Shinohara, Takao. (1997). Effects of cigarette smoking on cerebral blood flow in normal adults. Tokyo Ika Daigaku Zasshi (Journal of Tokyo Medical College); Journal Volume: 55; Journal Issue: 6; Other Information: PBD. 19-729.

15. Jobsis FF. (1977). Non-invasive infrared monitoring of cerebral and myocardial sufficiency and circulatory parameters. Science. 198: 1264-1267.

16. Obrig H. (2014). NIRS in clinical neurology - a 'promising' tool? Neuroimage. 85: 535-546.

17. Chia-Wei Sun, Ching-Cheng Chuang. (2012). Hemodynamics Study Based on Near-Infrared Optical Assessment. In: A Seda Artis, Hemodynamics - New diagnostic and therapeutic approaches. InTech pub. 47-89.

18. Crespi F. (2007). Near-infrared spectroscopy (NIRS): a non invasive in vivo methodology for analysis of brain vascular and metabolic activities in real time in rodents Current Vascular Pharmacology. 5(4): 305-321.

19. Crespi F, Congestri F, Donini M. (2018). Translational NIRS: Parallel Alteration of Brain Metabolism Following Alcohol Intake in Rodents and Man. J Neurodegener Disord. 2(1): 2231.

20. Karama S, Ducharme S, Corley J.F Chouinard-Decorte, J M Starr, J M Wardlaw, M E Bastin, I J Deary. (2015). Cigarette smoking and thinning of the brain's cortex. Mol Psychiatry. 20: 778-785.

21. Matcher SJ, Kirkpatrick PJ, Nahid K, et al. (1995). Absolute quantification methods in tissue near-infrared spectroscopy. SPIE 2389.

22. Scholkmann F, Kleiser S, Metz AJ, et al. (2013). A review on continuous wave functional near-infrared spectroscopy and imaging instrumentation and methodology. Neuroimage. 85: 627.

23. Metz CN. Gregersen PK. (2004). Malhotra AK. Metabolism and biochemical effects of nicotine for primary care providers. Medical Clinics of North America. 88(6):1399-413.

24. Kovacic P. Cooksy A. (2005). Iminium metabolite mechanism for nicotine toxicity and addiction: Oxidative stress and electron transfer. Medical Hypotheses. 64(1): 104-111.

25. Rogers AJ. Denk LD. Wax PM. (2004). Catastrophic brain injury after nicotine insecticide ingestion. Journal of Emergency Medicine. 26(2): 169-72.

26. Zanardi A. Leo G. Biagini G. Zoli M. (2002). Nicotine and neurodegeneration in ageing. Toxicology Letters. 127(1-3): 207-215.

27. Maggio R. Riva M. Vaglini F. Fornai F. Racagni G. Corsini GU. (1997). Striatal increase of neurotrophic factors as a mechanism of nicotine protection in experimental Parkinsonism. Journal of Neural Transmission. 104(10): 1113-1123.

28. R. McKendrick, H. Ayaz, R. Olmstead R. (2014). Parasuraman Enhancing dual-task performance with verbal and spatial working memory training: Continuous monitoring of cerebral hemodynamics with NIRS. NeuroImage. 85, 3: 1014-1026

29. Sae Uchida, Harumi Hotta. (2009). Cerebral Cortical Vasodilatation Mediated by Nicotinic Cholinergic Receptors: Effects of Old Age and of Chronic Nicotine Exposure Biological and Pharmaceutical Bulletin. 32, 3: 341-344. https://doi.org/10.1248/bpb.32.341

30. Crespi F. (2005). Dihydropyridines, Nitric Oxide and Vascular Protection. Current Vascular Pharmacology. 3.

31. S Pogun, S Demirgoren, D Taskiran, L Kanit, O. Yilmaz, E.O. Koylu, B. Balkan, E.D.London. (2000). Nicotine modulates nitric oxide in rat brain. European Neuro psychopharmacology, 10, 6: 463-472. https://doi.org/10.1016/S0924977X(00)00116-4

32. Crespi F, M Donini, A Bandera, F Congestri, F Formenti, V Sonntag, et al. (2006). Near-infrared oxymeter biosensor prototype for non-invasive in vivo analysis of rat brain oxygenation: effects of drugs of abuse. J. Opt. A: Pure Appl. Opt. 8: 528-534.

33. Stein EA. (2001). FMRI: a new tool for the in vivo localization of drug actions in the brain. Journal of Analytical Toxicology. 25(5): 419-424.

34. Bloom AS. Hoffmann RG. Fuller SA. Pankiewicz J. Harsch HH. Stein EA. (1999). Determination of drug-induced changes in functional MRI signal using a pharmacokinetic model. Human Brain Mapping. 8(4): 235-244.

35. Ferrari M, Quaresima V. (2012). A brief review on the history of human functional near-infrared spectroscopy (fNIRS) development and fields of application. Neuroimage. 63: 921935.

36. Hoshi Y, Huang J, Kohri S, et al. (2011). Recognition of human emotions from cerebral blood flow changes in the frontal region: A study with event-related near-infrared spectroscopy. J Neuroimaging. 21: 94-101.

37. Kono T, Matsuo K, Tsunashima K, et al. (2007). Multiple-time replicability of near-infrared spectroscopy recording during prefrontal activation task in healthy men. Neurosci Res. 57: 504-512.

38. Molteni E, Contini D, Caffini M, et al. (2012). Load-dependent brain activation assessed by time-domain functional nearinfrared spectroscopy during a working memory task with graded levels of difficulty. J Biomed Opt. 17: 056005. 

(c)

To Submit Your Article Click Here: Submit Manuscript

DOI: $10.31579 / 2693-4779 / 067$
Ready to submit your research? Choose Auctores and benefit from:

$>$ fast, convenient online submission

$>$ rigorous peer review by experienced research in your field

$>$ rapid publication on acceptance

$>$ authors retain copyrights

$>$ unique DOI for all articles

$>$ immediate, unrestricted online access

At Auctores, research is always in progress.

Learn more auctoresonline.org/journals/clinical-research-and-clinicaltrials 